\title{
Sense of coherence and associated factors among university students in China: cross-sectional evidence
}

\author{
Janet Junqing Chu*, Mobarak Hossain Khan, Heiko J. Jahn and Alexander Kraemer
}

\begin{abstract}
Background: Sense of Coherence (SOC) is considered as a health-promoting resource; it is mainly developed before the age of 30. The multiple demands university students face, such as study-related stress and financial difficulty, could challenge their SOC development. This study aimed to: 1) investigate the association between SOC, socio-demographic and lifestyle-related characteristics; 2) assess the effect of perceived stress on SOC controlling for other variables among the Chinese university students. Analyses were done to derive a better view on possible strategies to strengthen students' SOC and with that to promote their health.

Methods: The data used were from a Chinese university student health survey $(N=1,853)$. Logistic regression analyses were used to explore the effects of varied socio-demographic, lifestyle-related variables on students' level of SOC, as well as the association between perceived stress and SOC controlling for other variables in the analysis.
\end{abstract}

Results: Both social support $(\mathrm{OR}=2.56[1.87-3.50])$ and better performance compared with peers $(\mathrm{OR}=1.64$ [1.15-2.34]) were associated with a stronger SOC. Not feeling isolated at university $(O R=1.60$ [1.04-2.47]) and satisfaction with the political situation $(\mathrm{OR}=2.05[1.57-2.67])$ were also associated with a stronger SOC. This counts also for high health awareness ( $O R=1.40$ [1.05-1.87]) and nutrition importance ( $O R=1.67$ [1.04-2.69]). Perceived stress $(\mathrm{OR}=0.81$ [0.79-0.83]) was negatively associated with a strong SOC when controlling for socio-demographic and lifestyle-related variables.

Conclusion: We suggest integrating stress coping, emotion management training programmes as well as measures promoting social integration for students and teachers at campus, promoting healthy behaviours, and creating a supportive learning environment as strategies for enhancing the SOC level of university students in China.

Keywords: Health, Salutogenic, Sense of Coherence, Social support, Stress, University students

\section{Background}

Salutogenic model, sense of coherence, health and university students

Based on the Salutogenic model an individual's health is determined by the interplay of environmental threats (stimuli), generalized resistance resources (GRRs) at one's disposal, and the strength of one's sense of coherence (SOC) [1-3]. SOC has been defined as a construct at the centre of a human information-processing system

\footnotetext{
* Correspondence: janet_junqing.chu@uni-bielefeld.de

Department of Public Health Medicine, School of Public Health, Bielefeld University, Universitaetsstr. 25, 33615 Bielefeld, Germany
}

aimed to resolve conflicts and endure the inevitable stress of human life [1,4]. This construct is a global orientation to view the world and the individual environment as comprehensible, manageable and meaningful; therefore, SOC reflects three components: comprehensibility, manageability and meaningfulness [1]. A high SOC protects people from stress by the way they perceive life events as challenges not threats (sense of meaningfulness), occurring for a reason not inexplicable (sense of comprehensibility) and that, even if not under their own personal control, they can be handled by some other resource at their disposal instead of 
feeling overwhelmed and helpless (sense of manageability) $[1,5]$. The value of the salutogenic model, the link between SOC and health has been established by research. Studies in Europe and the US that involved large representative samples showed the correlation of SOC with measures of somatic and psychological health [6-9]. The SOC is considered as a healthpromoting resource that supports the development of a positive state of mental health [8]. Research shows that mental health promotion is most effective when it takes place early in a person's life, school-based interventions with a whole setting approach that embrace a more positive view of health can promote health and positive development of youth [10]. The SOC is tested and reinforced mainly in childhood and early adulthood, the years before the age of 30 are the most important period regarding the development of SOC $[1,11]$. University students belong to this age group. After coming from a usually familiar environment to the university, an environment with many new demands, students face numerous obstacles and developmental issues such as difficulties of managing academic challenges, deepening relationships with others, expanding social horizon, and choosing and planning a career [12]. Particularly academic tasks and demands at the university have been considered as a normative source of stress that could challenge the SOC of the students. In a longitudinal study among university students in Israel, Carmel \& Bernstein [13] found that the SOC level was negatively associated with work load. The authors concluded that the SOC level systematically decreased over time when the work load for the students increased. The university environment has also been reported as a context of socialisation, where people interact with one another and gain practical experiences to increase the ability of drawing the best conclusions in any situations [14]. The process of SOC development has been understood as an internalization of external resources, which were once at the individual's disposal and ultimately could reduce the present need for other resources [15, 16]. Based on Antonovsky [17] during the development of SOC, each new experience of successful stress management reinforces the SOC of the individual, and offers him/her better coping resources to be available in the future tension events. Our knowledge about how stress perception influences SOC among Chinese higher education students, who undergo relatively high level of perceived stress, remains incomplete. Additionally, although China houses more than one-fifth of the world's university/college students [18], most of the studies in the last decades focusing on SOC in adolescents and young people were conducted outside China, particularly in Scandinavian countries (44\%) and Israel (21 \%) [19]. Therefore, China represents scarcity of information.
Furthermore, the present study differs from most of the previous studies, which considered the SOC as a determinant of health. Briefly, as an important attempt to fulfil the abovementioned gaps, this research intended to identify the factors associated with SOC among the university students in China with emphasis on the impact of the perceived stress on the development of SOC. The specific aim was to: 1) investigate the association between SOC, socio-demographic and lifestyle-related characteristics without adjusting for perceived stress-model $1 ; 2$ ) assess the effect of perceived stress on SOC controlling for other variables-model 2 .

\section{Conceptual framework}

According to the Salutogenic model, the movement towards the optimal end of the health continuum requires a strong SOC, a good health status in turn can facilitate the acquisition of GRRs, therefore strengthens one's SOC [17]. Antonovsky stated that the effects of stressors and the GRRs at one's disposal together shape one's life experiences [1]. GRRs create life experiences, characterised by consistency, underload-overload balance, and participation in socially valued decision-making, give rise to a strong SOC. The absence of some GRRs, such as money or social ties, can become a stressor. Stressor can also be defined as life experiences characterised by inconsistency, under-, or overload, and exclusion from participation in decision-making $[1,17,20]$. We recapped Antonovsky's Salutogenic model of health ([1], p. 184-185) in the academic context as Fig. 1. The actual associations of GRRs and stress on SOC may be explained in two directions. In the development of SOC, an individual's perception of available GRRs intensifies one's SOC. In turn, a strong SOC enables an individual to mobilize whatever GRRs are at his or her disposal to deal with stressors [1]. Similarly, continual exposure to stressors weakens one's SOC. On the other hand, individuals with a strong SOC avoid stressors more easily, whereas those with a weak SOC are more likely to interpret stressors as threatening [1]. We are aware that the analysis presented in this paper is not able to test the reciprocal relationship between the factors presented in Fig. 1. Our analysis is driven by the theoretical assumption that a strong SOC is negatively associated with stressors and positively associated with perceived GRRs. It was hypothesised that higher level of perceived stress is associated with lower level of SOC; while GRRs such as social support, good relation with peers, and preventive health orientation such as physical activity and health awareness is positively associated with a strong SOC. Our study findings could provide insight into factors that may refine, reinforce, or modify students' SOC, therefore assist developing programmes to strengthen the students' health at Chinese universities. 


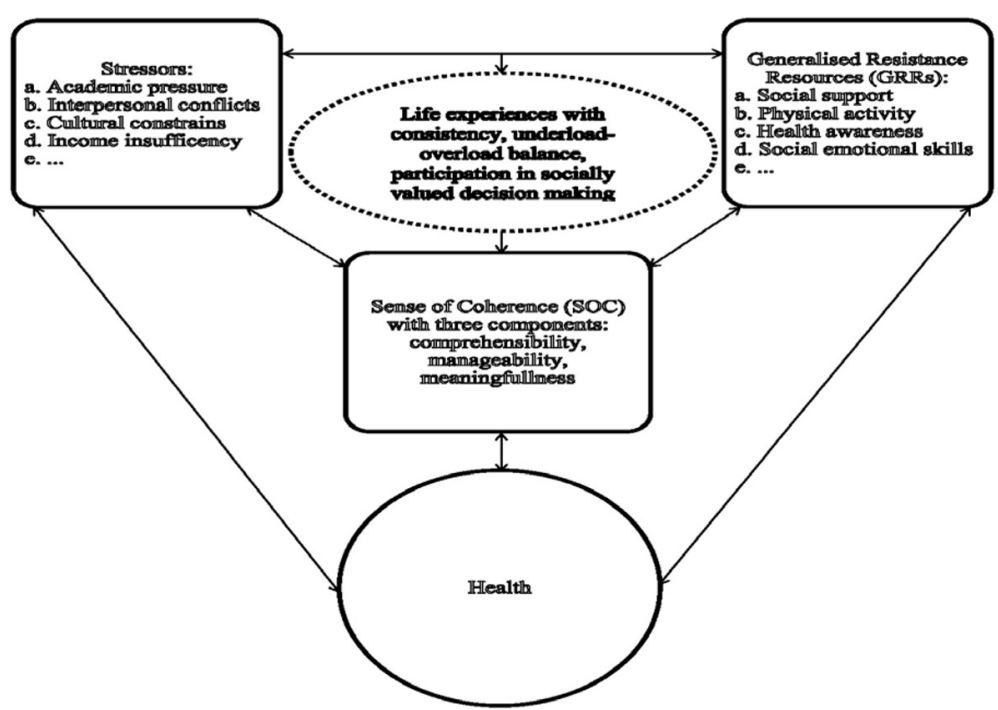

Fig. 1 Relation between Stressors, Generalized Resistance Resources and Sense of Coherence (adopted Antonovsky's Salutogenic model of health [Antonovsky, 1979, p. 184-185])

\section{Methods}

\section{Study location and questionnaire}

The data were obtained from a survey administered in 2010-2011 at two Chinese universities-Sun Yat-sen University (SYSU) in Guangzhou and Peking University (PKU) in Beijing. The employed self-administered questionnaire was an adjusted version of the standardized questionnaire, which was previously used for the Cross National Student Health Study (CNSHS) conducted in seven European countries in 1998-2005. At both universities, roughly one-third of the student sample was from the medical sciences, one-third from allied health sciences (dentistry, nursing, public health and pharmacy), and the rest from the natural sciences and economics with approximately $50 \%$ from each university. The response rate was above $90 \%$ at both universities. Altogether 1,853 students completed the questionnaire. The questionnaire was initially developed in English, in our survey the Chinese version was used. Prior to the survey, the standardized questionnaire was slightly modified to adapt it to the Chinese situation (such as, adding an item asking whether the student is an onlychild) and then translated by two independent researchers from English into Chinese. Two bilingual doctoral students examined the translated instruments. The two translated instruments were very close in meaning, indicating correct language transference. A pilot test was also conducted to a group of 32 undergraduate students at PKU before finalising the questionnaire. An ethical approval for the study was obtained from the Institutional Review Boards of Peking University. The students were asked to complete the survey questionnaires at the end of lectures in the lecture rooms. They were informed in writing that participation was voluntary and anonymous; they agreed to participate by completing and returning the questionnaire. No incentives were provided for participation in the survey. The research data used are available in our institutional repository PUB-Publications at Bielefeld University: http://doi.org/10.4119/unibi/2901280.

\section{Variables}

The following variables (with categories in parentheses for categorical variables) were selected for analysis:

\section{The sense of coherence (SOC)}

The SOC was assessed by the "Leipzig Short Scale" (SOC-L9) based on Antonovsky's 29-items Sense of Coherence Scale (SOC-29) scale [21]. This unidimensional scale consists of nine items based on a 7-point Likert scale. It has been validated in a representative German population sample of $N=2,005$ aged 18-92 years old. It was found as a reliable, valid and practicable instrument for measuring the SOC [21]. The SOC-L9 provides a single factor solution with high scores reflecting a strong SOC. A previous Chinese study among university students found a Cronbach's alpha of 0.73 for the SOC-L9 [22]. The total SOC score ranges from 9 to 63, with higher scores indicating higher SOC. For bivariable analysis and multivariable logistic regression, the total SOC-L9 sum score was dichotomized based on a median split yielding students having a strong SOC $(>42)$ and students having a weak SOC $(\leq 42)$, as the dependent variable. In our sample, Cronbach's alpha of the SOC-L9 was 0.77 . 


\section{Perceived stress}

Perceived stress was assessed by Cohen's 14-item Perceived Stress Scale (PSS-14), which measures the degree to which a respondent appraises situations in his or her life during the previous four weeks as stressful [23]. These 14 items used 5-point Likert scale responses. The total score (called PSS score) was obtained by adding all 14 items. The score ranges from 0 to 56 , where higher scores indicated higher levels of stress. The psychometric properties of the PSS-14 have been evaluated in various cultures and countries with reported Cronbach's alpha of $0.75-0.89$ across studies [24]. Cronbach's alpha of the PSS-14 scale in our sample was 0.79 .

\section{Socio-demographic variables}

Age, gender, birth place ("countryside"/"small city"/ "large city"), Only-child status ("yes"/"no"), having religious beliefs ("yes"/"no"), degree of father's education ("at least college level" ["high"]/"lower than college level" ["low"]), subjective health status ("good"/"poor"), income sufficiency ("sufficient"/"insufficient"), importance of good grade ("important"/"unimportant"), performance compared with peers ("better"/"the same"/"worse"), having a partner ("yes"/"no"), satisfaction with social support ("satisfied"/"dissatisfied"), relation with parents ("good"/"poor"), relation with fellow students ("good"/ "poor"), relation with friends ("good"/"poor"), isolation at university ("yes"/"no"), and satisfaction concerning political situation ("satisfied"/“dissatisfied”).

\section{Lifestyle-related variables}

Physical activity frequency ("less than once a week"/ "once to twice a week"/"at least three times a week"), degree of health awareness ("high"/"low"), importance of nutrition ("important"/"unimportant"), BMI (calculated from self-reported weight and height using Metric BMI Formula: $\mathrm{BMI}=$ weight in kilograms divided by the square of height in meters), and satisfaction concerning weight ("satisfied"/“dissatisfied").

\section{Statistical analysis}

Frequencies and means were tabulated for descriptive analysis. Pearson's Chi-square tests and Mann-WhitneyU-tests were used to analyse the bivariable associations between SOC (strong vs. weak) and socio-demographic, lifestyle-related variables as well as PSS score. Based on our theoretical model, structural equation modeling (SEM) should be more efficient for the multivariable analysis. As most SEM applications rely on normal theory methods-such as maximum likelihood and generalized least squares-when estimating model parameters and testing model goodness of fit [25]. In the case that observed and latent variables are not normally distributed, standard errors and estimates of fit might not be accurate [26]. The method of Weighted Least Squares offers an alternative, asymptotically distribution-free approach, but a minimum sample size of 2,000 was proposed for obtaining satisfactory results [27]. Since the distribution of the SOC scale sum scores in our subjects was negatively skewed, and our sample was smaller than 2,000, we used SOC scale sum score median as cut-off value for multivariable logistic regression analyses. Binary logistic regression analysis was used by previous studies to assess the association between a strong SOC and relevant variables among university students and in general population $[28,29]$. In order to estimate the impact of perceived stress on SOC, we built two multivariable regression models to analyse the adjusted associations of independent variables under investigation with a strong SOC (dependent variable), one model (model 1) excluded perceived stress, and another model (model 2) included perceived stress as an independent variable in the regression. The analysis was performed with IBM SPSS statistics 21. For all tests, the significance level was set at 0.05 .

\section{Results}

Sample description is presented in Table 1. There were slightly more males than females $(52.1 \%$ vs. $47.9 \%)$ in the sample, the average age of the subjects was 20.8 ( \pm 2.2 ) years old. Around $90 \%$ of the students rated their health awareness as high, their subjective health, and their relations with parents, friends, as well as fellow students as good. More than $80 \%$ of the students reported sufficient income. The majority (73\%) of the students were satisfied with the social support they received. Only-children accounted for $60 \%$ of the sample. Around $30 \%$ of the students performed physical exercise less than once a week. More than half of the students (56.1\%) were satisfied with the political situation in China. Roughly $17 \%$ of the students felt isolation at the university.

The results of bivariable analysis between SOC and variables under investigation are presented in Table 2 . Income sufficiency and social support were both positively associated with SOC. Students who had high health awareness, had more physical activity and were satisfied with their weight reported stronger SOC. Selfperceived better study performance compared to peers, a good relation with fellow students, not feeling isolated at university, and satisfaction concerning political situation were also associated with a stronger SOC. Neither gender nor BMI was significantly associated with SOC while both age and perceived stress scores were negatively associated with SOC.

Table 3 presents the summary results (ORs and $95 \%$-confidence intervals) of two multivariable binary logistic regression models using SOC (strong $=1$; weak $=0$ ) as an outcome variable. Regression model 1 included gender, age 
Table 1 Sample description

\begin{tabular}{|c|c|c|}
\hline Variables & Categories & Number (\%) \\
\hline \multirow[t]{2}{*}{ Gender } & Male & $948(52.1)$ \\
\hline & Female & $873(47.9)$ \\
\hline \multirow[t]{2}{*}{ Father's education } & High & $810(45.8)$ \\
\hline & Low & $958(54.2)$ \\
\hline \multirow[t]{2}{*}{ Having religious beliefs } & No & $1521(83.7)$ \\
\hline & Yes & $297(16.3)$ \\
\hline \multirow[t]{2}{*}{ Income sufficiency } & Sufficient & $1466(81.2)$ \\
\hline & Insufficient & $339(18.8)$ \\
\hline \multirow[t]{2}{*}{ Only-child } & Yes & $1092(60.0)$ \\
\hline & No & $727(40.0)$ \\
\hline \multirow[t]{3}{*}{ Birth place } & Countryside & $596(32.8)$ \\
\hline & Small city & $623(34.3)$ \\
\hline & Large city ${ }^{a}$ & $598(32.9)$ \\
\hline \multirow[t]{2}{*}{ Subjective health } & Good & $1648(89.2)$ \\
\hline & Poor & $200(10.8)$ \\
\hline \multirow[t]{2}{*}{ Health awareness } & High & $1232(67.2)$ \\
\hline & Low & $601(32.8)$ \\
\hline \multirow[t]{2}{*}{ Nutrition importance } & Importance & $1616(89.3)$ \\
\hline & Unimportance & $193(10.7)$ \\
\hline \multirow[t]{3}{*}{ Physical activity } & $<1$ a week & $510(28.5)$ \\
\hline & 1-2 a week & $872(48.8)$ \\
\hline & $\geq 3$ a week & $406(22.7)$ \\
\hline \multirow[t]{2}{*}{ Weight satisfaction } & Satisfied & $860(47.4)$ \\
\hline & Dissatisfied & 955 (52.6) \\
\hline \multirow[t]{2}{*}{ Good grade importance } & Important & $1686(92.8)$ \\
\hline & Unimportant & $130(7.2)$ \\
\hline \multirow[t]{3}{*}{ Performance compared with peers } & Better & $640(35.3)$ \\
\hline & The same & $691(38.1)$ \\
\hline & Worse & $482(26.6)$ \\
\hline \multirow[t]{2}{*}{ Having a partner } & Yes & $567(31.4)$ \\
\hline & No & $1240(68.6)$ \\
\hline \multirow[t]{2}{*}{ Social support } & Satisfied & $1336(73.0)$ \\
\hline & Dissatisfied & $494(27.0)$ \\
\hline \multirow[t]{2}{*}{ Relation with parents } & Good & $1652(89.5)$ \\
\hline & Poor & $194(10.5)$ \\
\hline \multirow[t]{2}{*}{ Relation with fellow students } & Good & $1628(88.1)$ \\
\hline & Poor & $219(11.9)$ \\
\hline \multirow[t]{2}{*}{ Relation with friends } & Good & $1676(90.6)$ \\
\hline & Poor & $174(9.4)$ \\
\hline \multirow[t]{2}{*}{ Isolation at university } & No & $1531(83.1)$ \\
\hline & Yes & $312(16.9)$ \\
\hline \multirow[t]{2}{*}{ Political situation } & Satisfied & $1031(56.1)$ \\
\hline & Dissatisfied & $808(43.9)$ \\
\hline
\end{tabular}

Table 1 Sample description (Continued)

\begin{tabular}{lll}
\hline Sense of coherence scale score & Weak $(\leq 42)$ & $953(52.6)$ \\
& Strong $(>42)$ & $859(47.4)$ \\
& Mean (SD) & \\
Age & $20.8(2.2)$ \\
BMl & $20.5(2.7)$ \\
Perceived stress scale score & $24.7(7.7)$ \\
\hline
\end{tabular}

${ }^{a}$ Cities higher than county level

and all other socio-demographic and lifestyle-related variables that were significantly associated with SOC in bivariable analysis. Regression model 2 included all independent variables of model 1 plus PSS score. In both models, preventive health orientation such as high health awareness, paying more attention to nutrition was associated with a strong SOC. No isolation at the university, satisfaction concerning social support and the political situation were also related to a strong SOC. Better performance compared with peers and good subjective health were positively contributed to a strong SOC. The odds of reporting strong SOC was significantly lower among students with higher stress $(\mathrm{OR}=0.81$ per PSS score point increase) controlling for socio-demographic and lifestyle-related variables. Out of the nine independent variables that showed significant ORs in model 1 , seven remained significant in model 2. Adding the PSS score into the regression was helpful to understand the effect of PSS on SOC: It considerably increased the amount of variation explained by the model in the dependent variable-the SOC: Nagelkerke $\mathrm{R}$ square from 0.30 in model 1 increased to 0.53 in model 2 (Table 3 ).

\section{Discussion}

The SOC is a health-promoting psychological resource that strengthens one's capacity in dealing with environmental strain and stressful situations [14]. In order to promote health of university students in China by a salutogenic approach, our study tried to identify factors that influence students' SOC at Chinese universities. Being consistent with previous studies, we found that the SOC was negatively associated with the level of perceived stress [30, 31], and positively associated with academic performance [32, 33]. Similar to a Finnish study, we found that a strong SOC was stronger associated with social support than with socioeconomic status such as family education background, sufficient income, or with merely the existence of relationship such as having a partner [11]. Our findings that more physical activity, paying more attention to health and nutrition were positively associated with the SOC are consistent with the results from two longitudinal studies conducted among university students in Finland and in a general population in Sweden [34, 35]. Our results that being not 
Table 2 Bivariable analysis: associations of relevant variables with a strong sense of coherence (SOC) (SOC scale score median > 42)

\begin{tabular}{|c|c|c|c|}
\hline Variables & Categories & $\begin{array}{l}\text { SOC scale } \\
\text { score median }\end{array}$ & $p$-value \\
\hline \multirow[t]{2}{*}{ Gender } & Male & 42 & \\
\hline & Female & 42 & 0.589 \\
\hline \multirow[t]{2}{*}{ Father's education } & High & 43 & \\
\hline & Low & 41 & 0.079 \\
\hline \multirow[t]{2}{*}{ Having religious beliefs } & No & 42 & \\
\hline & Yes & 42 & 0.205 \\
\hline \multirow[t]{2}{*}{ Income sufficiency } & Sufficient & 43 & \\
\hline & Insufficient & 40 & $<0.001$ \\
\hline \multirow[t]{2}{*}{ Only-child } & Yes & 42 & \\
\hline & No & 42 & 0.035 \\
\hline \multirow[t]{3}{*}{ Birth place } & Countryside & 42 & \\
\hline & Small city & 42 & \\
\hline & Large city ${ }^{\mathrm{b}}$ & 43 & 0.482 \\
\hline \multirow[t]{2}{*}{ Subjective health } & Good & 43 & \\
\hline & Poor & 37 & $<0.001$ \\
\hline \multirow[t]{2}{*}{ Health awareness } & High & 43 & \\
\hline & Low & 39 & $<0.001$ \\
\hline \multirow[t]{2}{*}{ Nutrition importance } & Important & 43 & \\
\hline & Unimportant & 37 & $<0.001$ \\
\hline \multirow[t]{3}{*}{ Physical activity } & $<1$ a week & 40 & \\
\hline & 1-2 a week & 42 & \\
\hline & $\geq 3$ a week & 44 & $<0.001$ \\
\hline \multirow[t]{2}{*}{ Weight satisfaction } & Satisfied & 43 & \\
\hline & Dissatisfied & 41 & 0.015 \\
\hline \multirow[t]{2}{*}{ Good grade importance } & Important & 42 & \\
\hline & Unimportant & 40 & 0.282 \\
\hline \multirow{3}{*}{$\begin{array}{l}\text { Performance compared } \\
\text { with peers }\end{array}$} & Better & 44 & \\
\hline & The same & 43 & \\
\hline & Worse & 38 & $<0.001$ \\
\hline \multirow[t]{2}{*}{ Having a partner } & Yes & 43 & \\
\hline & No & 42 & 0.250 \\
\hline \multirow[t]{2}{*}{ Social support } & Satisfied & 44 & \\
\hline & Dissatisfied & 37 & $<0.001$ \\
\hline \multirow[t]{2}{*}{ Relation with parents } & Good & 43 & \\
\hline & Poor & 37 & $<0.001$ \\
\hline \multirow[t]{2}{*}{ Relation with fellow students } & Good & 43 & \\
\hline & Poor & 37 & $<0.001$ \\
\hline \multirow[t]{2}{*}{ Relation with friends } & Good & 43 & \\
\hline & Poor & 36 & $<0.001$ \\
\hline \multirow[t]{2}{*}{ Isolation at university } & No & 43 & \\
\hline & Yes & 37 & $<0.001$ \\
\hline
\end{tabular}

Table 2 Bivariable analysis: associations of relevant variables with a strong sense of coherence (SOC) (SOC scale score median > 42) (Continued)

\begin{tabular}{|c|c|c|c|}
\hline \multirow[t]{2}{*}{ Political situation } & Satisfied & 44 & \\
\hline & Dissatisfied & 39 & $<0.001$ \\
\hline Age & & & 0.026 \\
\hline BMI & & & 0.292 \\
\hline Perceived stress scale score & & & $<0.001$ \\
\hline
\end{tabular}

isolated at the university was related to a strong SOC are in line with the findings of previous studies, that experiences of rejection or exclusion were negatively associated with SOC $[36,37]$. Our results that good relation with fellow students was related to a strong SOC are consistent with the findings of a Japanese longitudinal study, generally interpersonal conflict had a negative effect on mean SOC scores [38]. Being consistent with Antonovsky's [1, 17] SOC theory and the findings of Hassmen et al [39] we found positive association between the SOC, satisfaction concerning political situation and general subjective health. Our results clearly verify the assumption of our conceptual framework: A strong SOC is negatively associated with stressors and positively associated with perceived GRRs; perceived stress has a strong adverse impact on SOC.

\section{Stress coping, emotion management and SOC}

A cross-cultural study suggests that compared to Japanese and Korean students, Chinese students experienced the highest level of stress [40]. Two studies show that the top academic stressors for western students were all related to examination whereas the major stressors among Chinese students were caused by severe competition with peers and the high parental expectation on performance [41, 42]. Our study also suggests that worse academic performance compared with peers and poor relation with fellow students were related to a weaker SOC. In line with the results of previous longitudinal studies that people who experienced higher levels of stress tended to have lower levels of SOC [30, 37], we found that lower level of perceived stress was associated with a strong SOC, perceived stress had a strong impact on explaining the SOC variability. These findings suggest direction for crisis intervention: Shaping stress responses towards the effective coping style which is associated with a strong SOC, and creating a less competitive but more supportive learning environment at university [43].

Coping includes both the ability to mobilise resources to solve the problem (instrumental), and the ability to 
Table 3 Odds Ratios (OR) with 95\%-confidence interval (95\%-Cl) for associations of relevant variables with a strong sense of coherence (SOC)

\begin{tabular}{|c|c|c|c|c|c|}
\hline \multirow[t]{2}{*}{ Variables } & \multirow[t]{2}{*}{ Categories } & \multicolumn{2}{|c|}{ Strong SOC-model $1^{a}$} & \multicolumn{2}{|c|}{ Strong SOC- model $2^{\mathrm{b}}$} \\
\hline & & OR & $95 \%-\mathrm{Cl}$ & OR & $95 \%-\mathrm{Cl}$ \\
\hline \multirow[t]{2}{*}{ Gender } & Male & 1.08 & $0.87-1.36$ & 1.05 & $0.81-1.37$ \\
\hline & Female (Ref.') & & & & \\
\hline \multirow[t]{2}{*}{ Income sufficiency } & Sufficient & 1.32 & $0.98-1.78$ & 1.13 & $0.80-1.60$ \\
\hline & Insufficient (Ref.) & & & & \\
\hline \multirow[t]{2}{*}{ Only-child } & Yes & 1.01 & $0.81-1.27$ & 0.96 & $0.73-1.26$ \\
\hline & No (Ref.) & & & & \\
\hline \multirow[t]{2}{*}{ Subjective health } & Good & $1.94^{* *}$ & $1.30-2.89$ & $1.72^{*}$ & $1.07-2.76$ \\
\hline & Poor (Ref.) & & & & \\
\hline \multirow[t]{2}{*}{ Health awareness } & High & $1.52^{* *}$ & $1.18-1.94$ & $1.40^{*}$ & $1.05-1.87$ \\
\hline & Low (Ref.) & & & & \\
\hline \multirow[t]{2}{*}{ Nutrition importance } & Important & $2.04^{* *}$ & $1.34-3.08$ & $1.67^{*}$ & $1.04-2.69$ \\
\hline & Unimportant (Ref.) & & & & \\
\hline \multirow[t]{2}{*}{ Weight satisfaction } & Satisfied & & & & \\
\hline & Dissatisfied (Ref.) & 1.02 & $0.82-1.28$ & 0.93 & $0.71-1.21$ \\
\hline \multirow[t]{3}{*}{ Physical activity } & < 1 a week (Ref.) & & & & \\
\hline & 1-2 a week & $1.32^{*}$ & $1.01-1.73$ & 1.14 & $0.83-1.57$ \\
\hline & $\geq 3$ a week & $1.61^{* *}$ & $1.17-2.21$ & 1.13 & $0.77-1.66$ \\
\hline \multirow[t]{3}{*}{ Performance compared with peers } & Better & $2.23^{* * *}$ & $1.66-3.01$ & $1.64^{* *}$ & $1.15-2.34$ \\
\hline & The same & $1.97^{* * *}$ & $1.48-2.62$ & $1.62^{* *}$ & $1.16-2.26$ \\
\hline & Worse (Ref.) & & & & \\
\hline \multirow[t]{2}{*}{ Social support satisfaction } & Satisfied & $3.20^{* * *}$ & $2.44-4.21$ & $2.56^{* * *}$ & $1.87-3.50$ \\
\hline & Dissatisfied (Ref.) & & & & \\
\hline \multirow[t]{2}{*}{ Relation with parents } & Good & 1.32 & $0.86-2.03$ & 1.10 & $0.68-1.79$ \\
\hline & Poor (Ref.) & & & & \\
\hline \multirow[t]{2}{*}{ Relation with fellow students } & Good & $1.72^{*}$ & $1.05-2.83$ & 1.17 & $0.67-2.07$ \\
\hline & Poor (Ref.) & & & & \\
\hline \multirow[t]{2}{*}{ Relation with friends } & Good & 1.17 & $0.69-2.03$ & 1.04 & $0.56-1.91$ \\
\hline & Poor (Ref.) & & & & \\
\hline \multirow[t]{2}{*}{ Isolation at university } & No & $2.54^{* * *}$ & $1.76-3.69$ & $1.60^{*}$ & $1.04-2.47$ \\
\hline & Yes (Ref.) & & & & \\
\hline \multirow[t]{2}{*}{ Political situation } & Satisfied & $2.25^{* * *}$ & $1.80-2.82$ & $2.05^{* * *}$ & $1.57-2.67$ \\
\hline & Dissatisfied (Ref.) & & & & \\
\hline \multicolumn{2}{|l|}{ Age increase per year } & 0.99 & $0.94-1.05$ & 0.85 & $0.89-1.02$ \\
\hline \multicolumn{2}{|l|}{ PSS score increase per point } & - & - & $0.81^{* * *}$ & $0.79-0.83$ \\
\hline
\end{tabular}

Model 1 included variables that were significantly associated with SOC in bivariable analysis (except PSS score); model 2 includes perceived stress scale score as an additional independent variable added to model 1

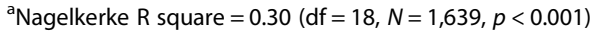

${ }^{\mathrm{b}}$ Nagelkerke R square $=0.53(\mathrm{df}=19, N=1,587, p<0.001)$

'Reference category; Significance of Wald test: ${ }^{*} p<0.05 ;{ }^{* *} p<0.01 ;{ }^{* *} p<0.001$

regulate emotions in the situation (emotional) [44]. Relevant information about stress, coping strategies, and emotion regulation is prerequisite for effective stress management since the availability of knowledge about how to handle difficult situations makes coping efforts more successful [17]. Intervention studies among university students indicated that emotion-related skills (i.e. the perception, use, understanding, and management of emotion) can be deliberately developed and enhanced through social emotional intelligence training [45-47]. 
Coping is not exclusive to the individual concerned, but also involves interaction between people and the society around them [48]. It was shown that students who have learnt how to control their own emotional reactions and to understand how others feel can deal better when facing difficulties with parents, peers and administrators, therefore consequently increase their "stress tolerance" and "optimism" in life [49]. Previous studies reported that inadequate social skills, lack of interpersonal communication skills, and criticism by others were among the major personal stressors in Chinese university students $[40,42]$. It was also reported that support from peers $[30,50]$ and teachers [51] was positively associated with the development of the SOC in adolescence. Our results concerning the positive association between good relation with fellow students, social support and the SOC are in line with these findings, and also highlight the major role of a good organizational climate at university for enhancing students' SOC as suggested by Feldt et al [52]. Adolescents and young people need to grow up in an environment that supports them to develop their individual potential, which also provides them with success models to look up to [53]. Socially and emotionally competent teachers can act as a role model to their students for respectful and appropriate interpersonal communication. They may also play an important role in coaching students through conflict situations and help establishing and implementing behavioural guidelines to promote cooperation and intrinsic motivation [49]. It was shown that social emotional intelligence training was an effective approach for promoting teachers' emotion-related skills and application of these skills in creating a supportive learning environment [49]. While we found that being not isolated at the university is related to a strong SOC, some researchers reported that teacher support and inclusive learning environment were associated with lower levels of stress in adolescents [54]. Therefore, we advocate integrating training programmes regarding stress coping strategy and emotion management for students and faculty into college curriculum.

\section{Social support, GRRs and SOC}

There is some overlap between the concepts of social support, social cohesion and GRRs in literature. Various researchers have defined social cohesion and social support differently, with some definitions much broader than the others [55]. As one of the most widely cited accounts in recent by Jenson ([56], p.15-17) social cohesion includes five dimensions: 1) Belonging (vs. isolation, refers to shared values and identity), 2) inclusion (vs. exclusion, looks at the equality of opportunity), 3) participation (vs. non-involvement, focuses on political participation), 4) recognition (vs. rejection, concerns the respect for diversity), 5) legitimacy (vs. illegitimacy, refers to major political and social institutions act as mediators in conflicts). Social support generally refers to resources supplied to individuals in need by their social network, it can be categorized into four types: 1) emotional support, refers to affect, esteem and concern, 2) instrumental support, reflects the availability of aid in labor, money and time, 3) appraisal support, means feedback and affirmation, and 4) informational support, refers to information, knowledge, and advice that are embedded in social networks [57]. Analytically, social support focuses primarily on the individual and group levels, like the networks maintained by individuals and the personal benefits that flow from them. Social cohesion, on the other hand, requires people's participation, cooperation and mutual help, is more concerned with the general condition of society [55]. In our study social support was measured as the individual's perception of the degree to which interpersonal relationships can provide in crisis situations. The GRRs include physical, biological, economic, and psychosocial sources, which can also be divided into internal (personal qualities) and external sources. Some examples of internal personal qualities are e.g. physical strength, knowledge-intelligence, and/or social emotional skills. Similarly examples of external factors are ability to provide social support, opportunities of education, or economic possibilities to satisfy daily needs [15]. Antonovsky [17] also stated that preventive health orientation is an important GRR. Our findings that paying more attention to health and nutrition were associated with a strong SOC support this statement [17]. Knowledge about balanced diet, contraception techniques, and information regarding vaccination station, consulting service at campus should be provided to students routinely as coping resources. We found age is not related to $\mathrm{SOC}$ in multivariable analysis, this is in line with the findings of most cross-sectional studies conducted in adolescents [19]. In adult population, some empirical studies found evidence for a continuous process of SOC through life $[58,59]$. While other studies pointed out that SOC was relatively stable in the high-SOC group, but not in the low-SOC group [5]. As Morrison \& Clift [6] found in a cohort study among adult students that SOC can be improved through peer support learning among students with low entry SOC scores [6].

Compared with the college students in Europe and the USA [60], students in our study reported less frequent physical activity. Meanwhile, our results that physical activity and good relation with fellow students were both positively associated with a strong SOC in model 1 , but not in model 2 when PSS score was added into the regression may provide clues about intervention in stress coping and SOC strengthening: Encouraging and facilitating sport events at Chinese campus may have multiple 
effects on promoting students' health: through strengthening physical strength, increasing chances for nurturing social support, reducing social isolation as well as interpersonal tension among peers. Based on Antonovsky's salutogenic concept, consistency, load-balance, and participation in socially-valued decision-making are the elements that provide basis for the three SOC components of comprehensibility, manageability and meaningfulness, respectively $[17,20]$. The lack of substantive complexity, disregarding people's potentials also leads to increasing paralysis of their sense of manageability [17]. In the Chinese context, emphasizing critical thinking, reducing rigidities of the educational system with its reliance on memory-based learning, and deregulating self-organised programs at campus may help strengthening the SOC of the students in particular [61]. Academic freedom and university governance are still the central developmental constraints for Chinese universities [62]. The extent to which people have a voice in what goes around them has significant influence on their level of meaningfulness [17]. Over control from the state on universities may discourage the participation of students in decision-making in their academic as well as social life in China, thus may negatively contribute to the development of a strong SOC within this population. Our finding that dissatisfaction with the political situation in China was related to weaker SOC of university students may give a hint in this regard. On the other hand stressors are more challenges to be welcomed than burden to be escaped in traditional Chinese cultural value, as the well-known philosophy of Mencius said: Whenever heaven invests an individual with great responsibilities, it first tries his/her resolve, exhausts his/her muscles and bones, starves his/ her body, leaves him/her destitute, and confounds his/her every endeavor. In this way his/her patience and endurance are developed, and his/her weakness is overcome [63]. According to Antonovsky [53], a complex culture can be a potential stressor but it also offers many possibilities of choice. Thus, for people who are flexible in choosing strategies, cultural constrains can even be SOC promoting. For instance, sharing social risk, pressure and burden of an interdependent society facilitates solidarity of the affected [64]. As Antonovsky suggested, high stressors can be salutary when accompanied by high levels of social supports [1].

\section{Limitations}

Our results must be interpreted in relation to some potential methodological limitations. The first limitation involves cultural adaptation, since we added two additional socio-demographic variables (only-child status and birth place) to the CNSHS questionnaire. This minor modification was necessary to respond the specific Chinese context, e.g. $60 \%$ of our subjects were only-children, as reported elsewhere that only-child status is associated with students' peer relation and their integration at the university [65]. Nevertheless, the main variables under investigation-SOC and PSS scales-should be culturally comparable since we used the official Chinese version of the two scales which are reliable, valid, and cross culturally applicable $[24,48]$. The second limitation concerns the sample, taken only from two universities, was over-represented by the students of medical and health sciences. Therefore, our results may not be transferable to all university students in China. Regarding the third limitation, given the cross-sectional character of our study, the results allow only conclusions about associations and not about causations. Finally, our data are based on self-reported information what may to a certain extent result in socially desired answers (in spite of the anonymous data collection situation) or incorrect information due to recall bias. However, despite these limitations our research has important strength. As to the best of our knowledge, no previous study have investigated in detail the associations of SOC with perceived stress, a wide range of socio-demographic and with lifestyle-related characteristics in a large sample of Chinese university students.

\section{Conclusion}

In conclusion, our study explored the effects of varied socio-demographic, lifestyle-related variables as well as perceived stress on students' level of SOC in university sitting in China. As reported in this paper, lower level of perceived stress, preventive health orientations, as well as integration at university are all related to a strong SOC. It is hoped that our findings could be useful in providing guidelines for interventions aiming to strengthen students' SOC, consequently to promote the health of students at Chinese universities.

\section{Abbreviations}

BMI: body mass index; CNSHS: the cross national student health study; GRRs: generalized resistance resources; OR: odds ratio; PKU: Peking University; PSS: perceived stress scale; SEM: structural equation modeling; SOC: sense of coherence; SYSU: Sun Yat-sen University; 95 \%-Cl: 95 \%-confidence interval.

Competing interest

We declare that there is no conflict of interest involved.

\section{Authors' contributions}

Kraemer A. and Chu JJ. conceived and designed the experiments; Chu JJ. and Jahn HJ. performed the experiments; Chu JJ. and Khan MH. analysed the data; Chu J., Khan MH., Jahn HJ. and Kramer A. all together wrote the paper. All authors read and approved the final manuscript.

\section{Acknowledgement}

We acknowledge support of the publication fee by Deutsche

Forschungsgemeinschaft and the Open Access Publication Funds of Bielefeld University.

Received: 28 October 2015 Accepted: 7 April 2016

Published online: 16 April 2016 


\section{References}

1. Antonovsky A. Health, Stress, and Coping: New Perspectives on Mental and Physical Well-Being. San Francisco: Jossey-Bass; 1979.

2. Bengel J, Strittmatter R, Willmann H. What keeps people healthy? The current state of discussion and the relevance of Antonovsky's salutogenic model of health. Research and practice of health promotion 1999. 4th ed. Cologne: Federal Centre for Health Education; 1999.

3. Lindström B, Eriksson M. Salutogenesis. J Epidemiol Community Health. 2005;59(6):440-2

4. Bonacci A, Miccinesi G, Galli SI, Chiesi FR, Martire M, Guazzini M, Toccafondi A, Fazzi LO, Balbo V, Vanni DU, Rosselli M. The dimensionality of Antonovsky's sense of coherence scales. An investigation with Italian samples. Testing, Psychometrics. Methodology Applied Psychology. 2012;19:115-34.

5. Hakanen JJ, Feldt T, Leskinen E. Change and stability of sense of coherence in adulthood: Longitudinal evidence from the Healthy Child study. J Res Personality. 2007:41(3):602-17.

6. Morrison I, Clift SM. Mental health promotion through supported further education: The value of Antonovsky's salutogenic model of health. Health Educ. 2006;106(5):365-80

7. Nilsson B, Holmgren L, Westman G. Sense of coherence in different stages of health and disease in northern Sweden: gender and psychosocial differences. Scand J Prim Health Care. 2000;18(1):14-20.

8. Eriksson $\mathrm{M}$, Lindström B, Lilja J. A sense of coherence and health. Salutogenesis in a societal context: Åland, a special case? J Epidemiol Community Health. 2007;61(8):684-8.

9. Lindström B, Eriksson M. The salutogenic approach to the making of HiAP/ healthy public policy: illustrated by a case study. Glob Health Promot. 2009; 16(1):17-28.

10. Sancassiani F, Pintus E, Holte A, Paulus P, Moro MF, Cossu G, Angermeyer MC, Carta MG, Lindert J. Enhancing the emotional and social skills of the youth to promote their wellbeing and positive development: a systematic review of universal school-based randomized controlled trials. Clin Pract Epidemiol Mental Health. 2015;11(1 M2):21.

11. Volanen SM, Suominen S, Lahelma E, Koskenvuo M, Silventoinen K. Sense of coherence and its determinants: A comparative study of the Finnish-speaking majority and the Swedish-speaking minority in Finland. Scand J Public Health. 2006;34(5):515-25.

12. Togari T, Yamazaki Y, Takayama TS, Yamaki CK, Nakayama K. Follow-up study on the effects of sense of coherence on well-being after two years in Japanese university undergraduate students. Pers Individ Dif. 2008:44(6):1335-47.

13. Carmel S, Bernstein J. Trait anxiety, sense of coherence and medical school stressors: Observations at three stages. Anxiety Res. 1990;3(1):51-60.

14. Lindström B, Eriksson M. From health education to healthy learning: implementing salutogenesis in educational science. Scand J Public Health. 2011;39 Suppl 6:85-92.

15. Suominen S, Vahtera J. Sense of Coherence and the Strive for Life Control. Health, Wellness Social Policy. 2010;10:145-55.

16. Suominen S, Blomberc $H$, Helenius H, Koskenvuo M. Sense of coherence and health-does the association depend on resistance resources? A study of 3115 adults in Finland. Psychol Health. 1999;14(5):937-48.

17. Antonovsky A. Unraveling the mystery of health: How people manage stress and stay well. San Francisco: Jossey-Bass; 1987.

18. MOE (Ministry of Education of the People's Republic of China). 2012 National Educational Development Statistics Bulletin. 2013. http://www. chinanews.com/edu/2013/08-16/5173046.shtml. Accessed 22 Oct 2015.

19. Rivera F, García-Moya I, Moreno C, Ramos P. Developmental contexts and sense of coherence in adolescence: A systematic review. J Health Psychol. 2013;18(6):800-12.

20. Antonovsky A. The sense of coherence: An historical and future perspective. Isr J Med Sci. 1996;32(3-4):170-8.

21. Schumacher J, Brähler E. Sense of Coherence Scale-Leipziger Kurzform (SOC-L9). Bern: Huber; 2000.

22. Gao ZH, Yang SQ, Margraf J. Reliability and Validity Test for Leipzig Short Scale for Recording Sense of Coherence (SOC-L9) in Chinese. China J Health Psychology. 2013;9:025.

23. Cohen S, Kamarck T, Mermelstein R. A global measure of perceived stress. J Health Soc Behav. 1983;385-96.

24. Lee EH. Review of the psychometric evidence of the perceived stress scale. Asian Nurs Res. 2012;6(4):121-7.

25. Tomarken AJ, Waller NG. Structural equation modeling: Strengths, limitations, and misconceptions. Annu Rev Clin Psychol. 2005;1:31-65.
26. Moosbrugger $\mathrm{H}$, Schermelleh-Engel $\mathrm{K}$, Klein A. Methodological problems of estimating latent interaction effects. Methods Psychological Research Online. 1997;2(2):95-111.

27. Nachtigall C, Kroehne U, Funke F, Steyer R. Pros and Cons of Structural Equation Modeling. Methods Psychological Research Online. 2003;8(2):1-22.

28. Peker K, Bermek G, Uysal O. Factors related to sense of coherence among dental students at Istanbul University. J Dent Educ. 2012;76(6):774-82.

29. Stankūnas M, Kalediene R, Starkuviene S. Sense of coherence and its associations with psychosocial health: results of survey of the unemployed in Kaunas. Medicina (Kaunas). 2009;45(10):807-13.

30. Natvig GK, Hanestad BR, Samdal O. The role of the student: Salutogenic or pathogenic? Int J Nurs Pract. 2006;12(5):280-7.

31. Torsheim T, Aaroe LE, Wold B. Sense of coherence and school-related stress as predictors of subjective health complaints in early adolescence: interactive, indirect or direct relationships? Soc Sci Med. 2001;53(5):603-14.

32. Dorri M, Sheiham A, Hardy R, Watt R. The relationship between Sense of Coherence and toothbrushing behaviours in Iranian adolescents in Mashhad. J Clin Periodontol. 2010;37(1):46-52.

33. Kristensson P, Öhlund LS. Swedish upper secondary school pupils' sense of coherence, coping resources and aggressiveness in relation to educational track and performance. Scand J Caring Sci. 2005:19(1):77-84.

34. Kuuppelomäki M, Utriainen P. A 3 year follow-up study of health care students' sense of coherence and related smoking, drinking and physical exercise factors. Int J Nurs Stud. 2003:40(4):383-8.

35. Nilsson B, Holmgren L, Stegmayr B, Westman G. Sense of coherence Stability over time and relation to health, disease, and psychosocial changes in a general population: a longitudinal study. Scand J Public Health. 2003;31:297-304.

36. Lundberg B, Hansson L, Wentz E, Björkman T. Are stigma experiences among persons with mental illness, related to perceptions of self-esteem empowerment and sense of coherence? J Psychiatr Ment Health Nurs. 2009;16(6):516-22

37. Volanen SM, Suominen S, Lahelma E, Koskenvuo M, Silventoinen K. Negative life events and stability of sense of coherence: A five-year follow-up study of Finnish women and men. Scand J Psychol. 2007:48(5):433-41.

38. Takayama T, Asano Y, Yamazaki Y, Yoshii K, Nagasaka Y, Fukada J, et al. Sense of coherence, stressful life events and psychological health [Nihon kōshū eisei zasshi]. Japanese J Public health. 1999;46(11):965.

39. Hassmen P, Koivula N, Uutela A. Physical exercise and psychological well-being: a population study in Finland. Prev Med. 2000;30(1):17-25.

40. Kim KI, Won H, Liu X, Liu P, Kitanishi K. Students' stress in China, Japan and Korea: A transcultural study. Int J Soc Psychiatry. 1997;43(2):87-94.

41. Phelps L. Academic achievement of children in China: The 2002 Fulbright experience. Psychol Sch. 2005;42(3):233-9.

42. Li H, Lin CD, Bray MA, Kehle TJ. The measurement of stressful events in Chinese college students. Psychol Sch. 2005;42(3):315-23.

43. Amirkhan $\mathrm{JH}$, Greaves $\mathrm{H}$. Sense of coherence and stress: The mechanics of a healthy disposition. Psychol Health. 2003;18(1):31-62.

44. Lazarus RS, Folkman S. Stress, Appraisal, and Coping. New York: Springer; 1984.

45. Jordan PJ, Ashkanasy NM, Härtel CE, Hooper GS. Workgroup emotional intelligence: Scale development and relationship to team process effectiveness and goal focus. Human Resource Management Review. 2002; 12(2):195-214.

46. Fletcher I, Leadbetter P, Curran A, O'Sullivan H. A pilot study assessing emotional intelligence training and communication skills with 3 rd year medical students. Patient Education Counselling. 2009;76(3):376-9.

47. Groves KS, Pat McEnrue M, Shen W. Developing and measuring the emotional intelligence of leaders. J Management Development. 2008;27(2): 225-50.

48. Eriksson M, Lindström B. Validity of Antonovsky's sense of coherence scale: a systematic review. J Epidemiol Community Health. 2005;59(6):460-6.

49. Brackett MA, Katulak NA. Emotional intelligence in the classroom: Skill-based training for teachers and students. Applying emotional intelligence: A practitioner's guide. 2006;1-27.

50. Evans WP, Marsh SC, Weigel DJ. Promoting adolescent sense of coherence: Testing models of risk, protection, and resiliency. J Community Appl Soc Psychol. 2010;20(1):30-43.

51. Bowen GL, Richman JM, Brewster A, Bowen N. Sense of school coherence, perceptions of danger at school, and teacher support among youth at risk of school failure. Child Adolesc Social Work J. 1998;15(4):273-86. 
52. Feldt T, Kinnunen U, Mauno S. A mediational model of sense of coherence in the work context: a one-year follow-up study. J Organ Behav. 2000;21(4): 461-76.

53. Antonovsky A. Complexity, conflict, chaos, coherence, coercion and civility. Soc Sci Med. 1993;37(8):969-74

54. Jennings PA, Greenberg MT. The prosocial classroom: Teacher social and emotional competence in relation to student and classroom outcomes. Rev Educ Res. 2009;79(1):491-525.

55. Chan J, To HP, Chan E. Reconsidering social cohesion: Developing a definition and analytical framework for empirical research. Social Indicators Res. 2006;75(2):273-302.

56. Jenson J, Réseaux canadiens de recherche en politiques publiques. Réseau de la famille. Réseau de la famille. Mapping social cohesion: The state of Canadian research. Ottawa: Family Network, CPRN; 1998.

57. Gottlieb BH. Selecting and planning support interventions. Soc Support Measurement Intervention. 2000;25:195-220.

58. Feldt $T$, Leskinen $E$, Kinnunen $U$, Ruoppila I. The stability of sense of coherence: Comparing two age groups in a 5-year follow-up study. Personality Individual Differences. 2003;35(5):1151-65.

59. Smith PM, Breslin FC, Beaton DE. Questioning the stability of sense of coherence. Soc Psychiatry Psychiatr Epidemiol. 2003;38(9):475-84.

60. El Ansari W, Stock C, Phillips C, Mabhala A, Stoate M, Adetunji H, et al. Int J Environ Res Public Health. 2011:8(2):281-99.

61. Mohrman K. The emerging global model with Chinese characteristics. Higher Education Policy. 2008;21(1):29-48.

62. Ngok K, Guo W. The quest for world class universities in China: Critical reflections. Policy Futures in Education. 2008;6(5):545-57.

63. Mencius. Gaozi. Part II. Mengzi (translated by David Hinton). San Francisco: Counterpoint; 1998.

64. Schwartz JM. From domestic to global solidarity: The dialectic of the particular and universal in the building of social solidarity. J Soc Philos. 2007;38(1):131-47.

65. Chu JJ, Khan MH, Jahn HJ, Kraemer A. Only-Child Status in Relation to Perceived Stress and Studying-Related Life Satisfaction among University Students in China: A Comparison with International Students. PLoS One. 2015;10(12):e0144947.

\section{Submit your next manuscript to BioMed Central and we will help you at every step:}

- We accept pre-submission inquiries

- Our selector tool helps you to find the most relevant journal

- We provide round the clock customer support

- Convenient online submission

- Thorough peer review

- Inclusion in PubMed and all major indexing services

- Maximum visibility for your research

Submit your manuscript at www.biomedcentral.com/submit 